\title{
Direct Energy Conversion for Fast Reactors
}

Neil W. Brown, John Cooper, Douglas Vogt, George Chapline, Patrice Turchi, Troy Barbee, Jr.

Lawrence Livermore National Laboratory

Joseph Farmer, Consultant

July 2000

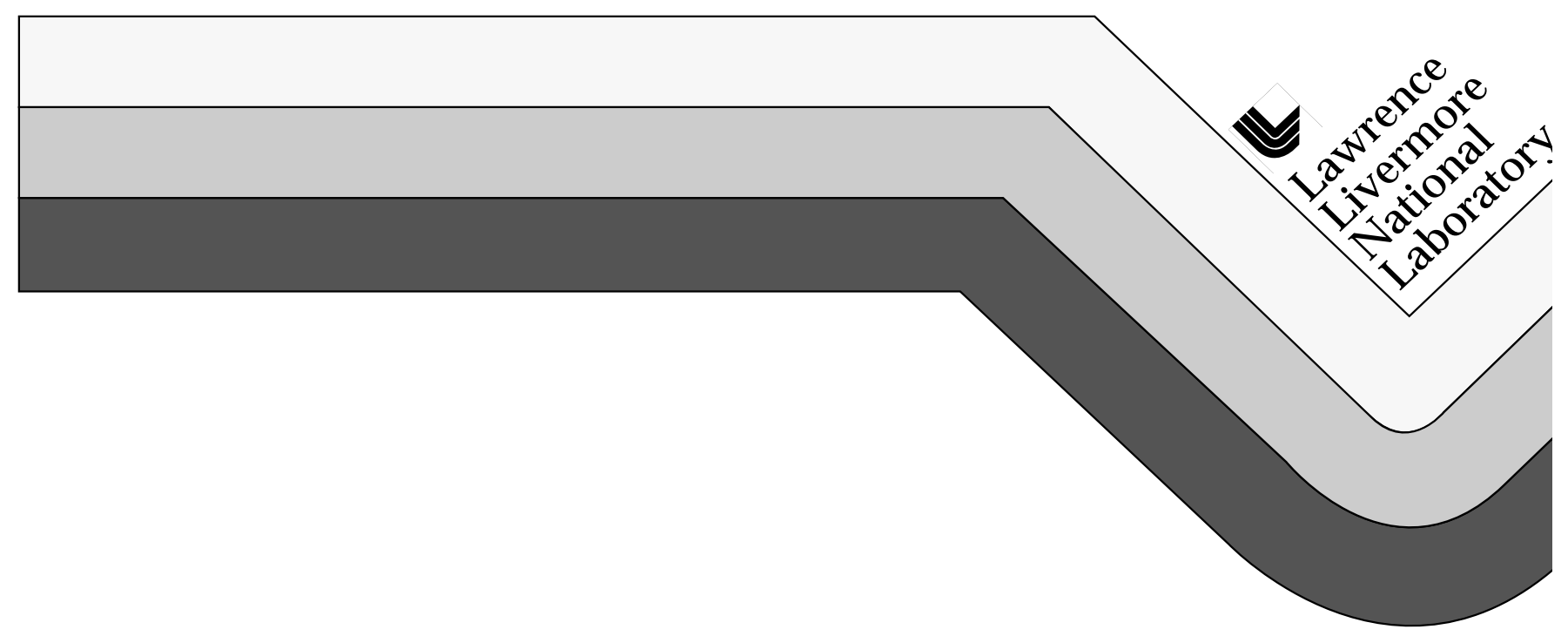


This document was prepared as an account of work sponsored by an agency of the United States Government. Neither the United States Government nor the University of California nor any of their employees, makes any warranty, express or implied, or assumes any legal liability or responsibility for the accuracy, completeness, or usefulness of any information, apparatus, product, or process disclosed, or represents that its use would not infringe privately owned rights. Reference herein to any specific commercial product, process, or service by trade name, trademark, manufacturer, or otherwise, does not necessarily constitute or imply its endorsement, recommendation, or favoring by the United States Government or the University of California. The views and opinions of authors expressed herein do not necessarily state or reflect those of the United States Government or the University of California, and shall not be used for advertising or product endorsement purposes.

Work performed under the auspices of the U.S. Department of Energy by Lawrence Livermore National Laboratory under Contract W-7405-ENG-48. 


\section{TABLE OF CONTENTS}

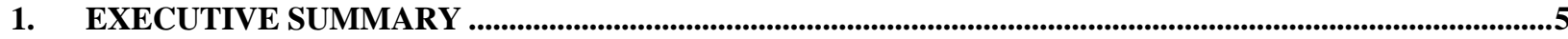

2. INTRODUCTION AND BACKGROUND ................................................................................................................

3. THERMOELECTRIC CONVERSION .....................................................................................................................

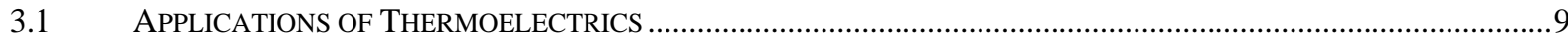

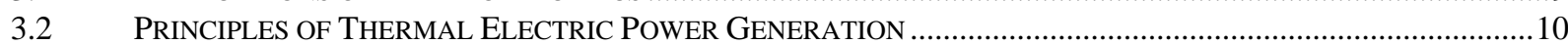

3.3 APPROACHES TO IMPROVING PERFORMANCE OF THERMAL ELECTRIC MATERIAL .......................................11

$3.4 \quad$ NEED FOR COMPUTATIONAL MATERIALS SCIENCE AND ENGINEERING........................................................16

4. ENGINEERING MATERIALS INTO LIQUID METAL HEAT EXCHANGERS FOR FAST REACTORS......................................................................................................................................................................17

5. RECOMMENDATIONS.................................................................................................................................................19

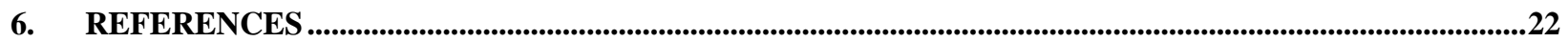

\section{FIGURES}

FIGURE 1.HEAT REJECTION FROM LIQUID METAL VIA DIRECT ENERGY CONVERSION

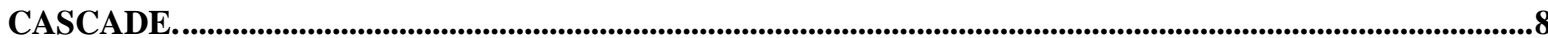

FIGURE 2.THERMODYNAMIC EFFICIENCY $(\eta)$ VERSES ZT FOR VARIOUS $\mathbf{T}_{\mathrm{C}} / \mathbf{T}_{\mathrm{H}}$ RATIOS

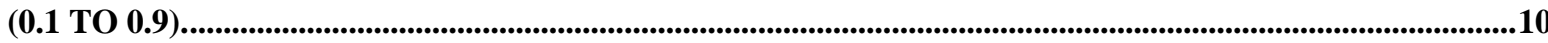

FIGURE 3. SP100 THERMOELECTRIC POWER CONVERTER ......................................................................17

FIGURE 4. SP100 FABRICATION TEST UNIT ............................................................................................................18

TABLE

TABLE 1. CHARACTERISTICS OF CANDIDATE THERMOELECTRIC MATERIALS (SOME ZT'S ESTIMATED 


\title{
Direct Energy Conversion for Fast Reactors
}

Neil W. Brown, John Cooper, Douglas Vogt, George Chapline, Patrice Turchi, \& Troy Barbee,Jr. Lawrence Livermore National Laboratory

\author{
Joseph Farmer, Consultant
}

\section{Executive Summary}

Thermoelectric generators (TEG) are a well-established technology for compact low power output long-life applications. Solid state TEGs are the technology of choice for many space missions and remote earth-based applications. Use of solid state TEGs in these applications requires engineering designs that minimize the weight and volume of the device. Thermal to electric conversion efficiency, while an important design consideration, is not the principal design factor. However, design of a TEG for a fast reactor nuclear power plant requires higher thermal efficiencies in order to achieve competitive power generation costs.

Over the last fifteen years, new thermoelectric (TE) materials have been developed and fabricated. These new materials including, skutterudites, offer the potential for improved thermal to electric conversion efficiency over certain temperature ranges. Today, solid state TE materials with thermal to electric conversion efficiencies of over $15 \%$, at their optimum temperature, are available. The normal operating outlet temperature of advanced reactors is approximately $823 \mathrm{~K}$ $(550 \mathrm{C})$. These power plants reject heat at temperatures of approximately $300 \mathrm{~K}\left(27^{\circ} \mathrm{C}\right)$. By combining TE materials, such as skutterudites, tellurides, and $\mathrm{PbTe} / \mathrm{Te}$ super lattice, each operating over a different temperature range, theoretical efficiencies approaching 25-30\% may be possible. The concept is shown in the following figure:

In addition to recent material advances, computational materials science (CMS) has provided a

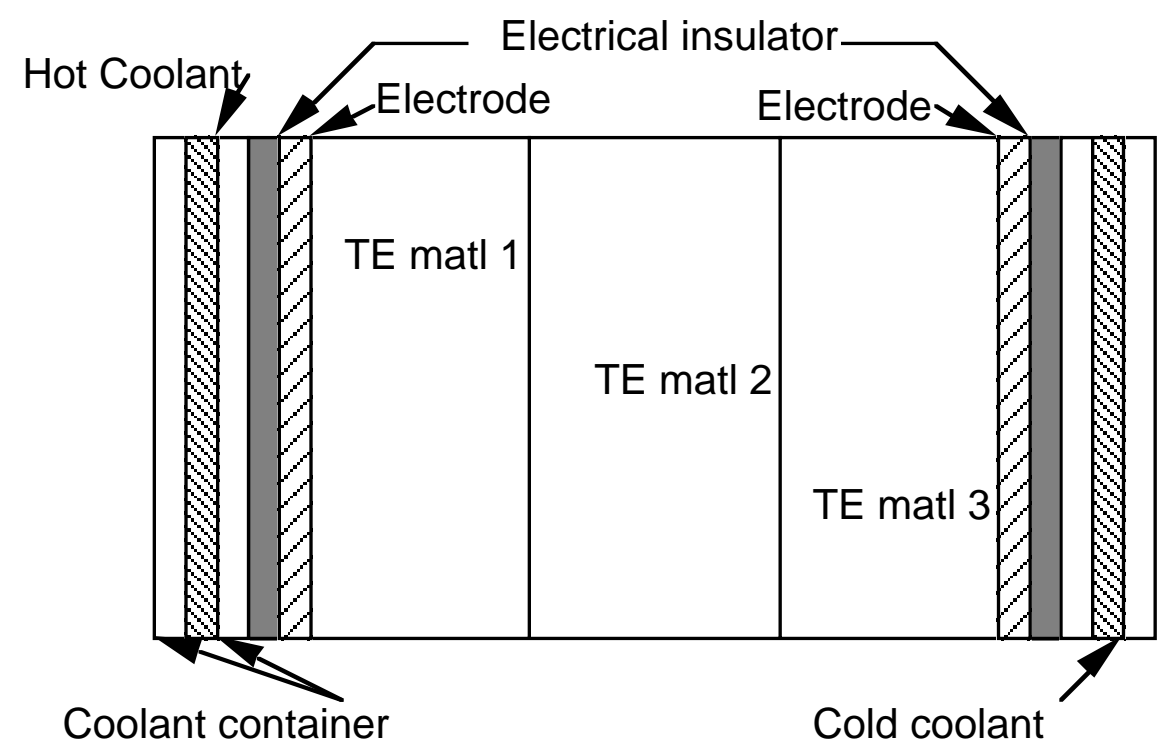


powerful tool to evaluate the potential of new TE materials. It is also possible with a magnetron sputtering source to efficiently evaluate thermoelectric properties of candidate materials. The combination of CMS and laboratory breakthroughs may provide a method to further optimize TEG design. With these tools it is possible to evaluate the effects of elemental change in TE solid state materials and fabrication methods on thermal-to-electric conversion efficiency.

The currently available TEG concept that could be most easily applied to a fast reactor power plant would use air cooling of TE elements bonded to the liquid metal coolant container surface. Such a design might be expected to have an efficiency of 5-10\%. The following sequence of investigation could lead to improvements in thermal efficiency that approach $25-30 \%$ in practical TEG equipment.

1. Through CMS and further review of current technology identify the optimum material for the air cooled TE elements.

2. Identify preferred materials through integrated CMS and laboratory research and optimize segmented multiple TE materials for use in the air cooled design.

3. Identify developmental materials that could be used to implement a liquid cooled TE element and its integration into a TEG design.

4. Assuming reactor structural and fuel materials suitable for $900 \mathrm{C}$ operations are developed, identify the TE materials and TEG configuration of a liquid cooled design.

The order of the investigation is based on an objective of matching the cost for efficiency gain with the perceived value of resulting efficiency. Step 1 will cost relatively little but the gain in efficiency is expected to result in a system efficiency that is still relatively low. Step 4 could be applied at Step 2 but it would be at a high cost with a gain in efficiency that would still leave the overall efficiency lower than the high development cost would justify. Step 3 is a very challenging design step and could result in a useful system, but Step 4 is likely to be necessary to achieve an efficiency in the range of $25-30 \%$. 


\section{Introduction and Background}

Thermoelectric generators (TEG) are a well-established technology for compact low power output long-life applications. Solid state TEGs are the technology of choice for many space missions and have also been used in remote earth-based applications.

Since TEGs have no moving parts and can be hermetically sealed, there is the potential for nuclear reactor power systems using TEGs to be safe, reliable and resistant to proliferation. Such power units would be constructed in a manner that would provide decades of maintenance-free operation, thereby minimizing the possibility of compromising the system during routine maintenance operations. It should be possible to construct an efficient direct energy conversion cascade from an appropriate combination of solid-state thermoelectric generators, with each stage in the cascade optimized for a particular range of temperature. Performance of cascaded thermoelectric devices could be further enhanced by exploitation of compositionally graded $p-n$ couples, as well as radial elements to maximize utilization of the heat flux. The Jet Propulsion Laboratory in Pasadena has recently reported segmented unicouples that operate between 300 and $975 \mathrm{~K}$ and have conversion efficiencies of 15 percent [Caillat, 2000].

TEGs are used in nuclear-fueled power sources for space exploration, in power sources for the military, and in electrical generators on diesel engines. Second, there is a wide variety of TE materials applicable to a broad range of temperatures. New materials may lead to new TEG designs with improved thermoelectric properties (i.e. ZT approaching 3) and significantly higher efficiencies than in designs using currently available materials. Computational materials science (CMS) has made sufficient progress and there is promise for using these techniques to reduce the time and cost requirements to develop such new TE material combinations. Recent advances in CMS, coupled with increased computational power afforded by the Accelerated Strategic Computing Initiative (ASCI), should improve the speed and decrease the cost of developing new TEGs.

The system concept to be evaluated is shown in Figure 1. Liquid metal is used to transport heat away from the nuclear heat source and to the TEG. Air or liquid (water or a liquid metal) is used to transport heat away from the cold side of the TEG. Typical reactor coolants include sodium or eutectic mixtures of lead-bismuth. These are coolants that have been used to cool fast neutron reactors. Heat from the liquid metal coolant is rejected through the thermal electric materials, thereby producing electrical power directly. The temperature gradient could extend from as high as $1300 \mathrm{~K}$ to $300 \mathrm{~K}$, although fast reactor structural materials (including those used to clad the fuel) currently used limit the high temperature to about $825 \mathrm{~K}$. 


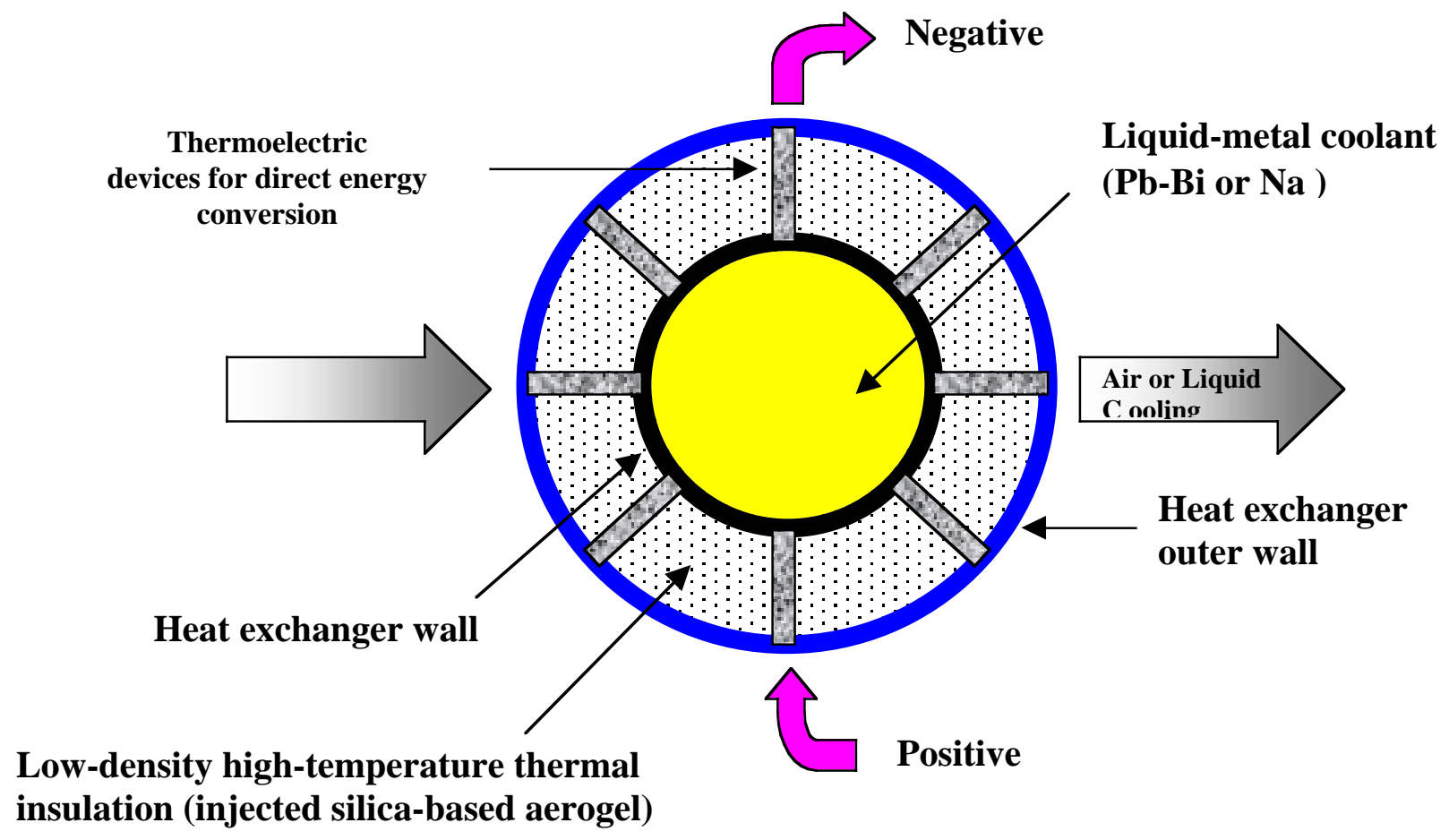

Figure 1. Heat rejection from liquid metal via direct energy conversion cascade. 


\section{Thermoelectric Conversion}

\subsection{Applications of Thermoelectrics}

The radioisotope-powered thermoelectric generator (RTG) has been used for many years by NASA to power their deep space probes [Voss, 1984; Lang \& Mastal, 1994]. These systems use Si-Ge unicouples that have hot surfaces at $1273 \mathrm{~K}$ and cold surfaces at $573 \mathrm{~K}$. The hot side is heated by radiation from the surface of graphite blocks that contain ${ }^{238} \mathrm{Pu}$ capsules and the cold side is conductively coupled to radiators that reject heat to space. At these temperatures the power system has an efficiency of 6 to 7 percent. If one were to use a similar approach at a temperature of $823 \mathrm{~K}\left(550^{\circ} \mathrm{C}\right)$, a typical reactor outlet coolant temperature, it can be seen from Figure 3 that the efficiency would drop to less than $5 \%$. If the maximum reactor coolant is $550^{\circ} \mathrm{C}$ then the hot thermoelectric material surface will be somewhat lower, even if bonded to the coolant boundary wall, and therefore the efficiency would be even lower.

The United States space power reactor (SNAP 10A) used a eutectic Na-K liquid to supply heat to a thermoelectric power converter. Russia has made extensive use of such devices and has placed more than thirty in orbit. The thermoelectric generators in SNAP 10A used $\mathrm{Pb}-\mathrm{Te}$ as the thermoelectric material. It is believed that the Russians use the same material.

Terrestrial based thermoelectric power systems have been used in various applications, typically for powering remote monitoring or signal transmitting stations. Various radioactive isotopes have been used as the heat sources and the thermoelectric power converters have used various thermoelectric materials. In all these applications the system efficiencies were of the order of $5 \%$ or less. This low efficiency is due not only to the low ZT but to the fact that there are inefficiencies associated with heat transfer from the heat source to the thermoelectric material and rejecting the heat to the environment.

Using a single currently available thermoelectric material and fabrication methods it may be possible to develop a thermoelectric power converter approaching $10 \%$ efficiency, using a reactor outlet coolant temperature of $550^{\circ} \mathrm{C}$ and a heat sink of $10^{\circ} \mathrm{C}$. Achieving this efficiency will require conductively coupling the TE material to the heat source and sink, and careful attention to design, manufacturing and assembly in order to minimize heat losses.

To achieve higher efficiencies both the $\mathrm{ZT}$ and the temperature difference across the thermoelectric materials must be increased. In addition, more than one thermal electric material must be used to make optimum use of the temperature difference, because the ZT of each thermoelectric material varies with temperature. For example, the ZT for Si-Ge is a maximum in the range of 1000 to $1200^{\circ} \mathrm{C}$ but decreases outside this range and is reduced by half its maximum at $600^{\circ} \mathrm{C}$. Therefore the average value of the ZT over the applied temperature range is less much than the peak value. Figure 2 shows variations of ZT as a function of temperature for typical thermoelectric materials. 


\subsection{Principles of Thermal Electric Power Generation}

Thermoelectric devices are p-n junctions in which charge carriers and heat flow in parallel. Electrons and holes must acquire energy at the p-n junction to flow in a direction opposite to the temperature gradient (from cold to hot). Both ohmic heating and heat conduction must be minimized for the efficient operation of such devices. The thermodynamic efficiency of a thermoelectric power generator $(\eta)$ is calculated from the dimensionless figure of merit (ZT). The dimensionless figure of merit, ZT, is determined by Seebeck coefficient $(\alpha)$, electrical conductivity $(\sigma)$, electronic thermal conductivity $\left(\kappa_{\mathrm{el}}\right)$, and lattice thermal conductivity $\left(\kappa_{\mathrm{ph}}\right)$.

$$
Z T=\frac{\sigma \alpha^{2}}{\kappa_{p h}+\kappa_{e l}} T
$$

The expressions for $\eta$ at the optimum current level is:

$$
\eta=\frac{T_{h}-T_{c}}{T_{h}} \frac{\sqrt{1+Z T}-1}{\sqrt{1+Z T}+T_{c} / T_{h}}
$$

where $T$ is the average temperature of the device, $T_{h}$ is the hot temperature and $T_{c}$ is the cold temperature [Equation 4-49, Angrist, 1976]. To achieve high values of $\eta$ with a thermoelectric device, a material with a large ZT value must be found [Vining, 1992]. The dependence of $\eta$ on $\mathrm{ZT}, \mathrm{T}_{\mathrm{c}}$, and $\mathrm{T}_{\mathrm{h}}$ is illustrated by Figure 2 .

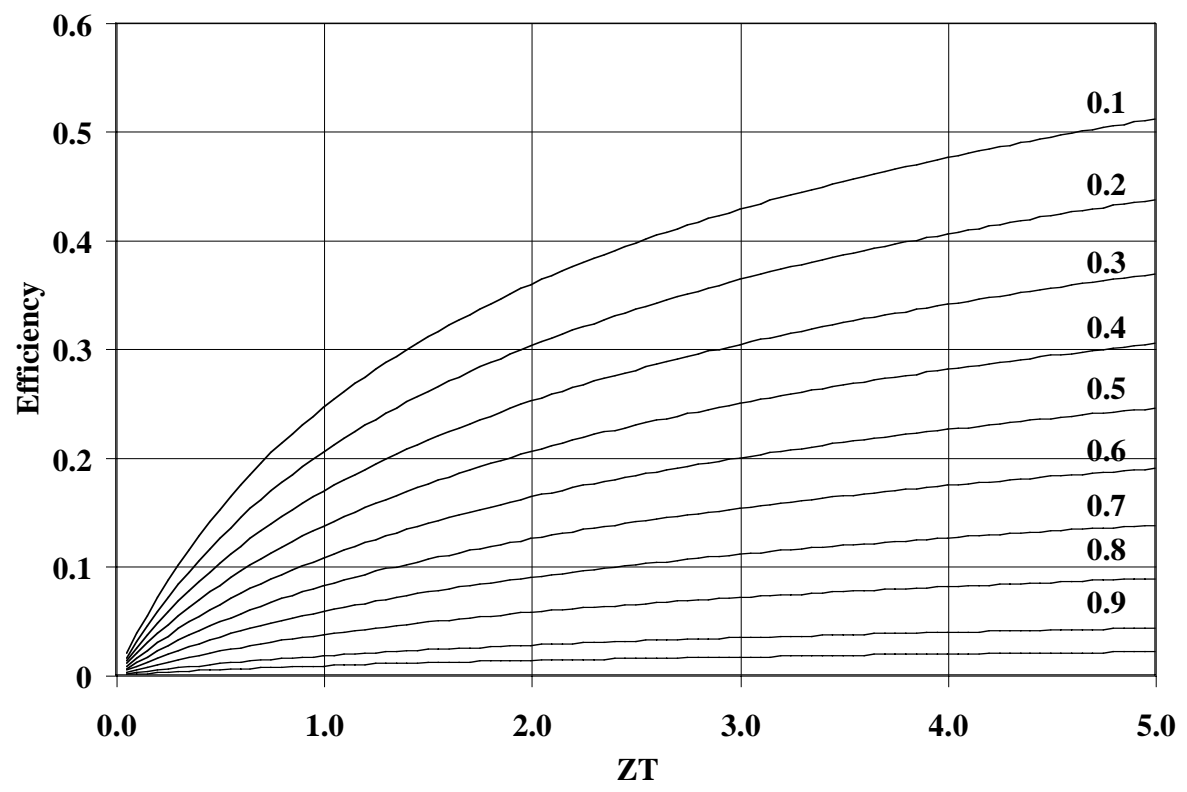

Figure 2. Thermodynamic efficiency $(\eta)$ verses $Z \mathrm{~T}$ for various $\mathrm{T}_{\mathrm{c}} / \mathrm{T}_{\mathrm{h}}$ ratios $(0.1$ to 0.9$)$. 
The thermodynamic efficiency of a TEG $(\eta)$ is calculated from the dimensionless figure of merit (ZT). Conventional thermoelectric materials $(\mathrm{ZT} \leq 1)$ are used in nuclear-fueled power sources for space exploration, in silent power sources for the military, and in solid-state electrical generators on diesel engines. By increasing ZT sufficiently, it should be possible to build TEG's that are competitive with more conventional power sources. In a cascaded TEG, SiGe-based couples could be used at high temperature $(1000 \mathrm{~K})$, PbTe-based couples could be used at intermediate temperatures $(600 \mathrm{~K})$, and $(\mathrm{Bi}, \mathrm{Sb})_{2}(\mathrm{Te}, \mathrm{Se})_{3}$-based couples could be operated at low temperatures $(300 \mathrm{~K})$. Such power units would be constructed in a way to provide decades of maintenance-free operation, thereby minimizing the possibility of compromising the system during routine maintenance operations.

It would be most desirable to construct the p-n couples of the TEG from well-known thermoelectric materials. These materials would be cascaded so the efficient high-temperature thermoelectrics are used closest to the nuclear heat source. Conventional materials such as nand p-type Si-Ge alloys could be used, provided that the operating temperature of the nuclear heat source is sufficiently high. At greater distances from the heat source, where the temperature would be lower, thermoelectric materials optimized for performance at the lower temperature would be employed. Materials proposed for operation at lower temperature include ( $\mathrm{Pb}, \mathrm{Sn}) \mathrm{Te}$, $(\mathrm{Ag}, \mathrm{Sb}) \mathrm{Te}_{2},(\mathrm{Bi}, \mathrm{Sb})_{2}(\mathrm{Te}, \mathrm{Se})_{3}$, and related materials. The TEG stage making contact with the hot surface of the TEG would probably be based upon $(\mathrm{Bi}, \mathrm{Sb})_{2}(\mathrm{Te}, \mathrm{Se})_{3}$. Alternatively, more stateof-the-art concepts could be used. For example, the Jet Propulsion Laboratory in Pasadena has recently reported segmented unicouples that operate between 300 and $975 \mathrm{~K}$ and have conversion efficiencies of 15 percent [Caillat, 2000]. The p-type leg of this device uses: $\mathrm{Bi}_{0.4} \mathrm{Sb}_{1.6} \mathrm{Te}_{3}$ between 300 and $475 \mathrm{~K} ; \beta-\mathrm{Zn}_{4} \mathrm{Sb}_{3}$ between 475 and $675 \mathrm{~K}$ and $\mathrm{CeFe}_{4} \mathrm{Sb}_{12}$ between 675 and $975 \mathrm{~K}$. The n-type leg of this device uses: $\mathrm{Bi}_{2} \mathrm{Te}_{2.95} \mathrm{Se}_{0.05}$ between 300 and $475 \mathrm{~K}$ and $\mathrm{CoSb}_{3}$ between 475 and $975 \mathrm{~K}$. This device was fabricated with uniaxial hot-pressing of powdered materials, with 25-micron thick palladium foil between the different segments of the legs. This methodology allows no interdiffusion and low contact resistance. $\mathrm{The} \mathrm{Bi}_{2} \mathrm{Te}_{3}-\mathrm{based}$ elements were soldered to the cold shoe (copper); the skutterudites were brazed to the hot shoe (niobium) with $\mathrm{Cu}-\mathrm{Ag}$ brazing alloy.

\subsection{Approaches to Improving Performance of Thermal Electric Material}

Promising thermoelectric materials should have high "power factors" $\left(\sigma \alpha^{2}\right)$ and low thermal conductivities $\left(\kappa_{\mathrm{ph}}+\kappa_{\mathrm{el}}\right)$. Furthermore, such materials should be plentiful enough (and sufficiently inexpensive) to enable the possible construction of large-scale devices. Degenerate semiconductors have the best combinations of these intrinsic properties [Cornish, 1959]. Strategies to find bulk thermoelectric materials with exceptional figures of merit require that we simultaneously increase $\sigma$ and $\alpha$, while decreasing $\kappa_{\mathrm{ph}}+\kappa_{\mathrm{el}}$. Unfortunately, improvements in $\sigma$ are accompanied by detrimental changes in $\kappa_{\mathrm{el}}$ since $\sigma$ and $\kappa_{\mathrm{el}}$ trend in the same direction (Wiedemann-Franz law). Since $\alpha, \sigma$, and $\kappa_{\mathrm{el}}$ are all sensitive to carrier concentration, ZT is optimized by changing the extent of doping. Overall increases in the optimum value of ZT are achieved by reducing $\kappa_{\mathrm{ph}}$ by other means. For example, semiconductor compounds made from elements with high atomic mass tend to have lower lattice thermal conductivities than those made from lighter elements. This is illustrated by Keyes' rule and similar expressions which correlate lattice thermal conductivity $\left(\kappa_{\mathrm{ph}}\right)$ with melting-point temperature $\left(\mathrm{T}_{\mathrm{m}}\right)$, atomic mass $(A)$, and density $(\rho)$. 


$$
\kappa_{p h}=\frac{B T_{m}^{3 / 2} \rho^{2 / 3}}{A^{7 / 6} T}
$$

where $\mathrm{B}$ is a constant and $\mathrm{T}$ is the temperature. It is evident that semiconductors with relatively low melting points should be used for low-temperature applications; i.e., as $\mathrm{T}$ is reduced, $\mathrm{T}_{\mathrm{m}}$ must be reduced to compensate. Furthermore, it is clear that materials made of elements with high atomic masses are preferred.

Bismuth Telluride. Materials favored for low-temperature applications include $\mathrm{PbTe}, 25 \% \mathrm{p}-$ type $\mathrm{Bi}_{2} \mathrm{Te}_{3}-75 \% \mathrm{Sb}_{2} \mathrm{Te}_{3}$ with $1.75 \%$ excess $\mathrm{Te}$, and n-type $75 \% \mathrm{Bi}_{2} \mathrm{Te}_{3}-25 \% \mathrm{Bi}_{2} \mathrm{Se}_{3} . \mathrm{Bi}_{2 \mathrm{x}} \mathrm{Sb}_{2(1-}$ ${ }_{x)} \mathrm{Te}_{3 \mathrm{y}} \mathrm{Se}_{(3-\mathrm{y})}$ compounds are rhombohedral and are classified as $\mathrm{V}$-VI narrow-band $(\leq 0.2 \mathrm{eV})$ semiconductors. These materials are stable at low temperatures, but disproportionate above 600 K. Dimensionless figures of merit (ZT's) for these materials have been published and are tabulated in Table 1 [Wood, 1988; Rosi, 1968]. The unusually low thermal conductivities of these bismuth-containing materials, which are less than $10 \mathrm{~mW} \mathrm{~cm}^{-1} \mathrm{~K}^{-1}$ at $300 \mathrm{~K}$, are due to the formation of a solid solution between isoelectronic, heavy-element, compound semiconductors. Such alloying is believed to lead to more intense scattering of phonons than electrons, thereby decreasing $\kappa_{\mathrm{ph}}$ without reducing $\sigma$ significantly [Wood, 1988; Ioffe, 1956]. The phonons responsible for heat conduction have wavelengths equivalent to a few interatomic spacings. Since the conduction of these phonons involves atomic motions, they are scattered most effectively by atomic-scale mass variations in the lattice. Fortunately, the scattering of charge carriers by such variations is minimal. If atoms of higher mass but similar valence and ionic size are substituted into a lattice, the effect on the periodic electrostatic potential of the lattice should be small. It has also been suggested that electrons in semiconducting compounds travel on the cation (metal atom) sublattice while holes move on the anion (non-metal atom) sublattice [Hyun, 1992; Wood, 1988]. Thus, defects in the cation sublattice will scatter electrons more strongly than defects in the anion sublattice. Furthermore, defects in the anion sublattice will scatter holes more strongly than defects in the cation sublattice. Therefore, in the case of Group V chalcogenides, the addition of $\mathrm{Bi}_{2} \mathrm{Se}_{3}$ to $\mathrm{Bi}_{2} \mathrm{Te}_{3}$ should produce a larger increase in the n-type figure of merit than the addition of $\mathrm{Sb}_{2} \mathrm{Te}_{3}$. The latter should produce better p-type material. A detailed model has been developed to predict the thermoelectric properties of this alloy system as a function of composition [Fleurial, 1992]. Several optical studies of this alloy system have also been done [Wakaki, 1992; Stordeur, 1992].

Silicon Germanium. The best known material for high-temperature TEG's is $\mathrm{Si}_{70} \mathrm{Ge}_{30}$ alloy [Cook, 1992; Slack, 1991; Vining, 1991; Wood, 1988; Rosi, 1968]. Usually, B is used as a dopant to produce p-type $\mathrm{Si}_{70} \mathrm{Ge}_{30}$. A combination of $\mathrm{P}$ and $\mathrm{GaP}$ can be used to produce n-type $\mathrm{SiGe}$. Si, Ge, and Si-Ge alloys have the well-known diamond structure. Dimensionless figures of merit (ZT's) for these materials have also been published and are tabulated in Table 1.

Sulfides. Published data for several transition metal and rare earth sulfides indicate that these materials are also good thermoelectric materials. Cutler and Leavy [1963-64] have investigated nonstoichiometric p-type $\mathrm{Ce}_{(3-\mathrm{x})} \mathrm{S}_{4}$. More recently, Kamarzin et al. [1981] and Gschneidner et al. [1982-88] have investigated n-type $\mathrm{La}_{(3-\mathrm{x})} \mathrm{S}_{4}$. In addition to samples made of pressed and sintered powders, single crystals have been studied. These materials are ionic compounds and maintain their bcc structure over the entire range of stoichiometries investigated. Unfortunately, oxysulfides form at high temperature, giving rise to problems with phase stability. Representative data are tabulated in Table 1. 
Silicides. We believe that it may be possible to achieve good performance at high temperature with pseudo-binary alloys of $(\mathrm{Fe}, \mathrm{Os}) \mathrm{Si}_{2}$. Studies have been conducted and published on several silicides, including doped $\mathrm{FeSi}_{2}, \mathrm{Cr}_{28} \mathrm{Si}_{72},\left(\mathrm{CrSi}_{2}\right)_{\mathrm{x}}\left(\mathrm{Cr}_{11} \mathrm{Ge}_{19}\right)_{1-\mathrm{x}}$, and $\mathrm{Ru}_{2} \mathrm{Si}_{3}$ [Birkholz, 1992; Matsubara, 1992; Gladun, 1992; Caillat, 1992; Ohta, 1992]. As shown in Table 1, the thermoelectric properties of these specific materials are poor. However, more recently, theoretical studies [van Ek, 1996; Turchi, 1998] have shown that alloying effects could be used to improve the thermoelectric properties of $\mathrm{FeSi}_{2}$. Recent developments in theoretical predictions of alloy stability and transport properties [Turchi, 1995, 1997, 1998; Mayou, 1998] will allow us to improve the performance at high temperature of pseudo-binary alloys such as $(\mathrm{Fe}, \mathrm{Os}, \mathrm{Ru}) \mathrm{Si}_{2}$. The same theoretical technology which is based on a real-space electronic structure description of multi-component alloys, will be also applicable to other geometries such as thin films and quantum wells.

Skutterudites. A variety of skutterudites have been explored by Jet Propulsion Laboratory (JPL) [Caillat, 2000]. Skutterudites can be represented by the general formulae $\operatorname{LnT}_{4} \operatorname{Pn}_{12}$ or $\operatorname{TPn}_{3}(\mathrm{Ln}$ $=$ rare earth; $\mathrm{T}=\mathrm{Fe}, \mathrm{Ru}, \mathrm{Os}, \mathrm{Co}, \mathrm{Rh}$, or Ir; \& Pn = P, As, or Sb) [Fleurial, 1996; Borschevsky, 1995]. Most recently, $\mathrm{CeFe}_{4} \mathrm{Sb}_{12}, \mathrm{CoSb}_{3}$, and $\mathrm{Zn}_{4} \mathrm{Sb}_{3}$ have been found to have very high dimensionless figures of merit $(\mathrm{ZT} \leq 1.4)$. For example: $\mathrm{p}$-type $\beta-\mathrm{Zn}_{4} \mathrm{Sb}_{3}$ has a $\mathrm{ZT}$ of 1.4 at 675 $\mathrm{K}$; p-type $\mathrm{CeFe}_{4} \mathrm{Sb}_{3}$ has a ZT of 1.4 at $900 \mathrm{~K}$; and n-type $\mathrm{CoSb}_{3}$ has ZT of 0.9 at $850 \mathrm{~K}$. Earlier materials in this class include covalent $\mathrm{IrSb}_{3}$, which has a cubic structure and a measured ZT of 0.50 at $773 \mathrm{~K}$ [Caillat, 1992]. Unfortunately, the use of iridium in practical thermoelectric devices may be limited by its expense.

High-Temperature Superconductors (HTSC's). The thermoelectric properties of several HTSC's have been determined [Macklin, 1990]. HTSCs are very poor thermoelectric materials. The best results were obtained for $\mathrm{YBa}_{2} \mathrm{Cu}_{3} \mathrm{O}_{6.3}(\mathrm{ZT} \approx 0.06$ at $300 \mathrm{~K})$.

Conductive Polymers. Published data for several conductive polymers have been collected and analyzed [Roy, 1991; Yoon, 1989-91; Maddison, 1988-89; Bender, 1987]. The best thermoelectric polymer appears to be polyacetylene doped with 6.6 atomic $\% \mathrm{FeCl}_{3}$ [Yoon, 1991]. Unfortunately, the dimensionless figure of merit of this material is also poor $(\mathrm{ZT} \approx 0.02$ at $300 \mathrm{~K})$. We are unaware of any conductive polymer with good thermoelectric properties. Furthermore, such materials are not suitable for high temperature applications.

Thermoelectric Thin Films. George and Pradeep [1985] and Charles et al. [1988] have prepared films of $\mathrm{Bi}_{2} \mathrm{Te}_{3}$ with excellent thermoelectric properties by reactive coevaporation, achieving stoichiometric composition through careful substrate temperature control. Boikov et al. [1989] reported stoichiometric films of the ternary compound, $\mathrm{Bi}_{0.5} \mathrm{Sb}_{1.5} \mathrm{Te}_{3}$ with thermoelectric properties approaching those of bulk single crystals using flash evaporation. Stolzer and Stordeur [1992] have used planar magnetrons to deposit single-layer $\mathrm{Bi}_{0.5} \mathrm{Sb}_{1.5} \mathrm{Te}_{3}$ films onto $\mathrm{Si} / \mathrm{SiO}_{2}$ wafers. Mobilities observed in the films were approximately 5 times lower than those observed in single crystals. This disappointing reduction in mobility was attributed to the scattering of charge carriers by imperfections, though the work appears to be inconclusive. The best work on sputtered films of $(\mathrm{Bi}, \mathrm{Sb})_{2}(\mathrm{Te}, \mathrm{Se})_{3}$ was recently published by Noro, Sato, and Kagechika [1993]. The Seebeck coefficient $(\alpha)$ and electrical conductivity $(\sigma)$ were measured at ambient temperature. Measurements were made for films prepared with different substrate and annealing temperatures. These investigators conclude that potentially, sputtered polycrystalline films can have the same thermoelectric performance as bulk single crystals. 
Two-Dimensional Quantum Wells. No dramatic improvement in the dimensionless figure of merit, i.e. beyond ZT $>1$, has been achieved during the past thirty years. However, Hicks and Dresselhaus of MIT have recently developed a model for the thermoelectric properties of 2D quantum wells, which has led to some promising predictions [1992-93]. They have derived expressions for $\alpha, \sigma, \kappa_{\mathrm{el}}$, and $\mathrm{Z}$ of such quantum wells. Their model assumes that electrons occupy only the lowest subband of the quantum well, which is consistent with the optimization of $\mathrm{Z}$ arising from a one-band model, and that there is no quantum-mechanical tunneling through the wide-gap semiconductor. The wide-gap semiconductor does not contribute to the electrical conduction since its carriers have found lower-energy states in the narrow-gap semiconductor.

As described by Dresselhaus, Harmon has used molecular beam epitaxy at MIT Lincoln Laboratory to produce $\mathrm{PbTe} / \mathrm{Te}$ superlattices that appear to have $\mathrm{ZT}_{3 \mathrm{D}} \sim 1.9$. In these twodimensional quantum wells, it is believed that both the barrier and quantum well layers are contributing to the figure of merit. The quantum well and barrier layers have about the same thickness. In early theoretical predictions, the contributions of the barrier layer were not accounted for. More recently, Dresselhaus et al. have extended their model to account for partial confinement of carriers in the quantum well. In addition to the effects of quantum well confinement, other factors may also be responsible for the unusually high figure of merit found with these two-dimensional structures. For example, phonon scattering from the interfaces between layers would lower thermal conductivity, and thereby enhance the figure of merit.

The possibility of creating two-dimensional quantum-well (2D QW) with greatly enhanced dimensionless figures of merit (ZT) has also been explored through the actual synthesis of such structures with multi-magnetron sputtering [Farmer et al., 1994; Wagner et al., 1995-96]. It is believed that such process technology would be required for practical fabrication of economically-viable devices. While these devices were not found to have average bulk properties as great as anticipated from theoretical predictions, the program developed synthesis processes capable of producing thermoelectric thin films of the best quality known. In some cases, these films appeared to have figures of merit approaching those of bulk single crystals. This work was pursued to the point where miniature Peltier coolers were fabricated from the thermoelectric thin films.

One-Dimensional Quantum Wells. Theoretical predictions indicate that an appropriately engineered 1D QW might also have an enhanced dimensionless figure-of-merit [Hicks and Dresselhaus, 1993]. Some believe that carbon nanotubes might behave like like such QWs. To investigate this possibility, investigators at Lawrence Berkeley National Laboratory (another site operated by the University of California) and Rice University have prepared films osf singlewalled carbon nanotubes [Hone et al., 1998]. Unfortunately, the $\mathrm{ZT}_{3 \mathrm{D}}$ observed with these films does not appear to be greater than the values achievable with more conventional materials. 
Table 1. Characteristics of Candidate Thermoelectric Materials (some ZT's estimated)

Family

Tellurides

Si-Ge Alloys

Silicides

Sulfides

Skutterudites

HTSCs

Polymers

Superlattice
Type \& Compound

$\begin{array}{ll}\mathrm{p} & \mathrm{Bi}_{0.5} \mathrm{Sb}_{1.5} \mathrm{Te}_{3} \\ \mathrm{n} & \mathrm{Bi}_{2} \mathrm{Te}_{1.4} \mathrm{Se}_{0.6} \\ \mathrm{p} & \mathrm{Bi}_{0.4} \mathrm{Sb}_{1.6} \mathrm{Te}_{3} \\ \mathrm{n} & \mathrm{Bi}_{2} \mathrm{Te}_{2.85} \mathrm{Se}_{0.15} \\ \mathrm{p} & \mathrm{PbTe} \\ \mathrm{n} & \mathrm{PbTe}_{\mathrm{nTe}} \\ \mathrm{n} & \mathrm{Pb}_{0.75} \mathrm{Sn}_{0.25} \mathrm{Te} \\ \mathrm{p} & \left(\mathrm{GeTe}_{0.95}\left(\mathrm{Bi}_{2} \mathrm{Te}_{3}\right)_{0.05}\right. \\ \mathrm{p} & \mathrm{AgSbTe}_{2} \\ \mathrm{p} & {\mathrm{Amorphous} \mathrm{As}_{2} \mathrm{Te}_{3}}\end{array}$

$\begin{array}{ll}\mathrm{p} & \mathrm{Si}_{70} \mathrm{Ge}_{30} \\ \mathrm{n} & \mathrm{Si}_{70} \mathrm{Ge}_{30}\end{array}$

$\begin{array}{ll}\mathrm{n} & \mathrm{FeSi}_{2}+3 \% \mathrm{Co} \\ \mathrm{p} & \mathrm{Ru}_{2} \mathrm{Si}_{3} \\ \mathrm{n} & \mathrm{Ru}_{2} \mathrm{Si}_{3}\end{array}$

$\begin{array}{ll}\mathrm{p} & \mathrm{Ce}_{3-\mathrm{x}} \mathrm{S}_{4}(0.00<\mathrm{x}<0.33) \\ \mathrm{p} & \mathrm{Ce}_{3-\mathrm{x}} \mathrm{S}_{4}(0.30<\mathrm{x}<0.33) \\ \mathrm{n} & \mathrm{LaS}_{1.445} \\ \mathrm{p} & \mathrm{US}\end{array}$

$\begin{array}{ll}\mathrm{p} & \beta-\mathrm{Zn}_{4} \mathrm{Sb}_{3} \\ \mathrm{p} & \mathrm{CeFe}_{4} \mathrm{Sb}_{12} \\ \mathrm{n} & \mathrm{CoSb}_{3} \\ \mathrm{p} & \mathrm{IrSb}_{3}\end{array}$

$\mathrm{p} \quad \mathrm{YBa}_{2} \mathrm{Cu}_{3} \mathrm{O}_{6.3}$

p Polyacetylene $+\mathrm{FeCl}_{3}$

$\mathrm{PbTe} / \mathrm{Te}$
$\mathrm{T}(\mathrm{K})$ ZT Source

$\begin{array}{lll}300 & 0.98 & \text { Rosi, } 1968\end{array}$

$300 \quad 0.72 \quad$ Rosi, 1968

$350 \quad 1.05 \quad$ Caillat, 2000

$350 \quad 0.90 \quad$ Caillat, 2000

$\begin{array}{lll}600 & 1.05 & \text { Rosi, } 1968\end{array}$

$\begin{array}{lll}600 & 1.05 & \text { Rosi, } 1968\end{array}$

$900 \quad 1.44 \quad$ Wood, 1988

$\begin{array}{lll}750 & 1.28 & \text { Wood, } 1988\end{array}$

$\begin{array}{lll}650 & 1.17 & \text { Wood, } 1988\end{array}$

$773 \quad 0.33 \quad$ Mott, 1979

$1000 \quad 1.00 \quad$ Rosi, 1968

$1000 \quad 1.10 \quad$ Rosi, 1968

$1000 \quad 0.08 \quad$ Matsubari, 1992

$700 \quad 0.002$ Ohta, 1992

$500 \quad 0.006$ Ohta, 1992

$1000 \quad 0.43 \quad$ Cutler, 1964

$1000 \quad 1.03 \quad$ Cutler, 1964

$1000 \quad 1.53 \quad$ Kamarzin, 1981

$573 \quad 0.06 \quad$ Gmelin

$675 \quad 1.40 \quad$ Caillat, 2000

$900 \quad 1.40 \quad$ Caillat, 2000

$850 \quad 0.90 \quad$ Caillat, 2000

$773 \quad 0.50 \quad$ Caillat, 1992

$300 \quad 0.06 \quad$ Macklin, 1990

$300 \quad 0.02 \quad$ Yoon, 1991

1.9 Harman, 1998 


\subsection{Need for Computational Materials Science and Engineering}

The design and construction of economically viable TEG fast reactor systems will require the design, optimization, and fabrication of cascaded thermoelectric units in a way to most efficiently utilize the available heat flux and thermal gradient. For example, the Jet Propulsion Laboratory in Pasadena has recently reported segmented unicouples that operate between 300 and $975 \mathrm{~K}$ and have conversion efficiencies of 15 percent [Caillat, 2000]. The p-type leg of this device uses: $\mathrm{Bi}_{0.4} \mathrm{Sb}_{1.6} \mathrm{Te}_{3}$ between 300 and $475 \mathrm{~K} ; \beta-\mathrm{Zn}_{4} \mathrm{Sb}_{3}$ between 475 and $675 \mathrm{~K}$ and $\mathrm{CeFe}_{4} \mathrm{Sb}_{12}$ between 675 and $975 \mathrm{~K}$. The n-type leg of this device uses: $\mathrm{Bi}_{2} \mathrm{Te}_{2.95} \mathrm{Se}_{0.05}$ between 300 and $475 \mathrm{~K}$ and $\mathrm{CoSb}_{3}$ between 475 and $975 \mathrm{~K}$. This device was fabricated with uniaxial hotpressing of powdered materials, with 25-micron thick palladium foil between the different segments of the legs. This methodology allows no interdiffusion and low contact resistance. The $\mathrm{Bi}_{2} \mathrm{Te}_{3}$-based elements were soldered to the cold shoe (copper); the skutterudites were brazed to the hot shoe (niobium) with $\mathrm{Cu}-\mathrm{Ag}$ brazing alloy. The nuclear heat source would have to be engineered in such a way to provide phase stability at a relatively high operating temperature. Detailed understanding of long-term aging effects such as the possible amorphization of a ceramic heat source is essential. There are also substantial issues regarding the stability of barrier layers for the thermoelectric units.

Optimal materials are needed for the cascaded thermolectric generator. It may be possible to advantageously exploit combinatorial synthesis techniques for the design of optimal materials [Xiang et al., 1995]. The method is based on a combination of thin film deposition and physical masking techniques, and uses a parallel synthesis of spatially addressable libraries of solid-state materials. Arrays containing different combinations, stoichiometries, and deposition sequences can be generated and analyzed for optimal determination of materials properties. The technique has been successfully applied to the discovery of a new class of cobalt oxide magnetoresistance materials [Briceno et al., 1995]. This technique could be advantageously applied in the present context for optimizing the cascaded generator, but also for improving the figure of merit of each individual unit constituting the generator.

It may be possible to exploit combinatorial synthesis techniques for the design of optimal materials. Newly developed theoretical tools [Mayou et al., 1998] which combine on the one hand the accurate knowledge of microscopic material parameters (electronic transport, width of the band gap, etc.) obtained from ab initio methods, and on the other hand, the experimental determination of transport coefficients will provide a more accurate evaluation than done in the past of the figure of merit ZT which characterizes the efficiency of thermoelectric materials. The synergistic effort between experiment and theory will provide the necessary framework for designing and processing an optimized generation of cascaded thermoelectric units. 


\section{Engineering Materials into Liquid Metal Heat Exchangers for Fast Reactors}

In addition to developing improved thermoelectric material it is necessary to engineer the material into a power conversion heat exchanger. To maximize the performance of the power conversion heat exchanger it is necessary to have a direct conduction path from the hot coolant boundary wall to the TE material and from the thermoelectric material into the cold coolant boundary wall. The cold wall would most likely be cooled by a liquid, possibly another liquid metal or water. In addition, because many individual thermoelectric couples must be connected electrically there is an electrical circuit that must be insulated from the coolant boundary walls. This electrical insulator needs to have a high thermal conductivity since it must be in the thermal conduction path through the thermoelectric materials. The thermal electric material is typically rather brittle and it is therefore necessary to reduce the thermal stress that may be present because of the temperature differences and differences in coefficients of thermal expansion in the various materials. Selection of the geometry and inserting materials to match thermal coefficients of expansion is a necessary part of engineering the system and will usually lead to reducing the temperature difference across the TE material and the overall efficiency.

Figure 3 illustrates the approach used in the SP100 TEG design to address these constraints. This represents the most recent U.S. development effort on nuclear thermoelectric power system.
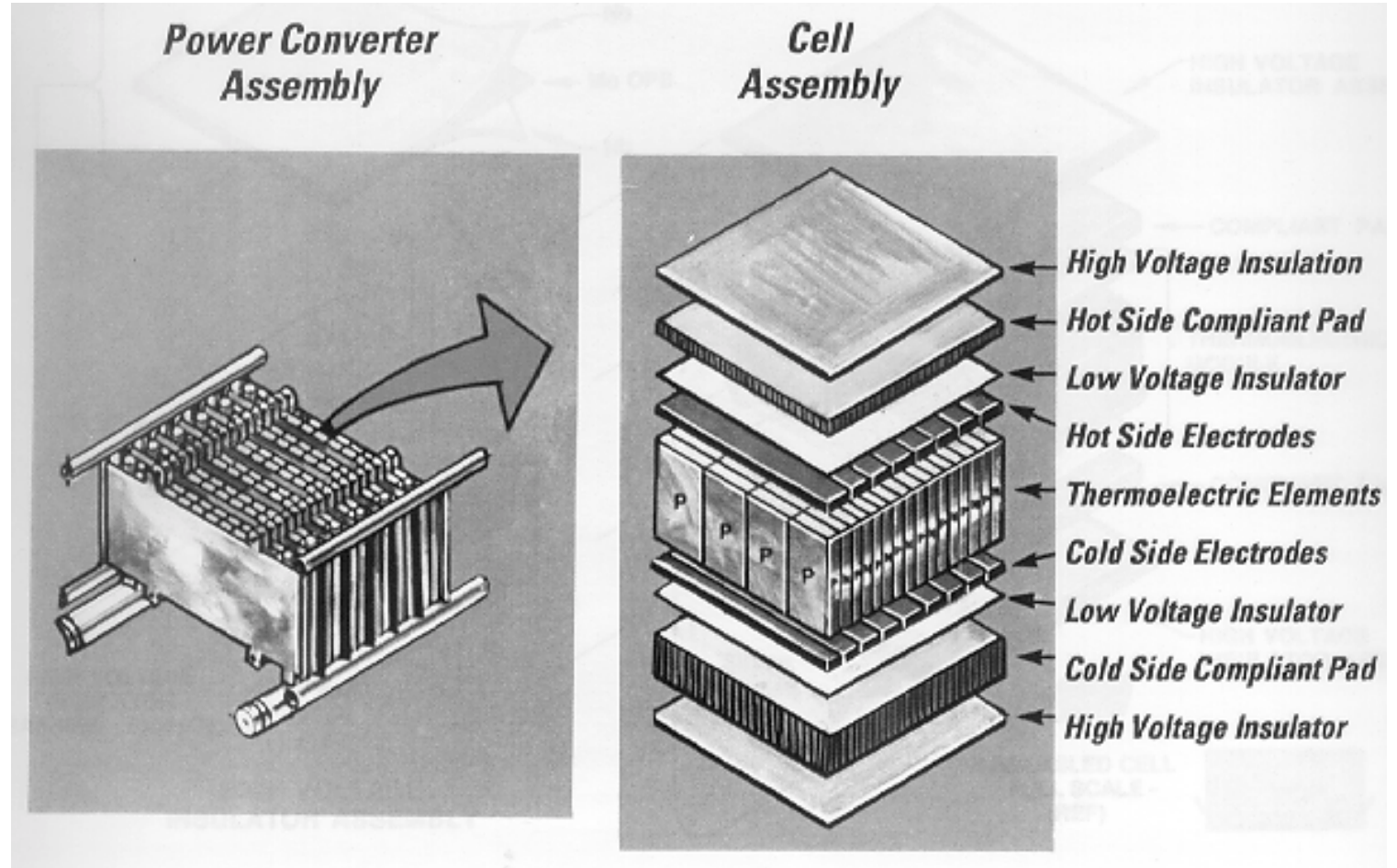

Figure 3. SP100 Thermoelectric Power Converter 
It was designed for operation in space at temperatures much higher that possible in an air atmosphere. The hot side of the heat exchanger was at $1032 \mathrm{C}$ and the cold side was at 590C.

These were flat plate heat exchangers that were bonded to multi-couple cells through electrical insulators and multi-fiber devices call compliant pads. The compliant pads were used to reduce the thermal stress in the TE material. Figure 4 illustrates a fabrication test unit that incorporates $48 \mathrm{TE}$ cells, the peak power cells producing 13 watts, and the unit power is 500 watts.

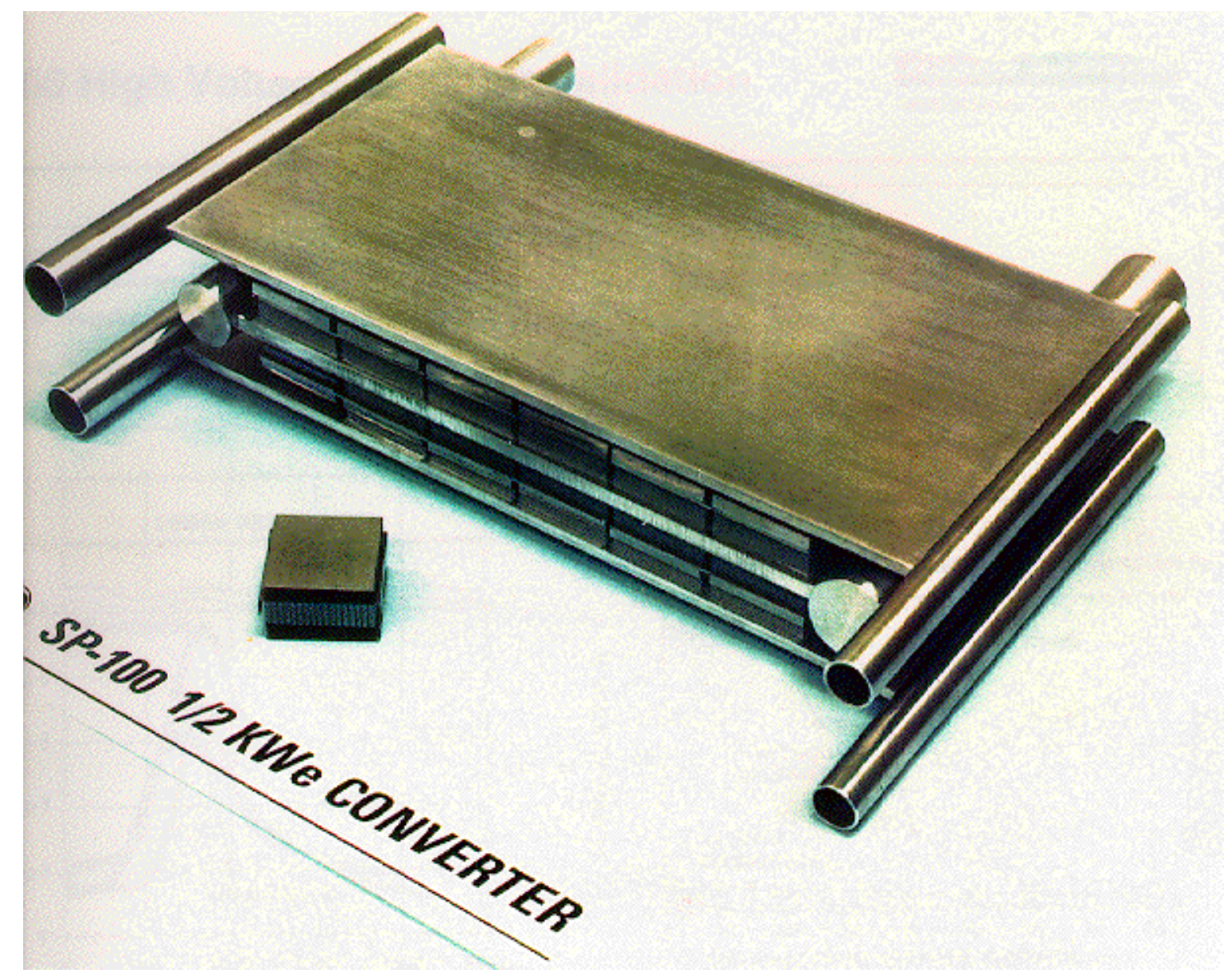

Figure 4. SP100 Fabrication Test Unit

A flat plate heat exchanger assembly like this could be used in a terrestrial design also, but it would require considerable more piping for the hot and cold coolants than is desirable. An approach that would support more conventional heat exchanger design would be to place the TE material between concentric tubes with the hot coolant flowing on the inside and the cold coolant flowing over the tube bundle. This approach has the advantage of placing the brittle thermoelectric material in compression and it might eliminate the need for compliant pads. Many units and the associated piping may still be required to provide a useful power level. A 25MW plant would require more than 25,000 three meter tubes, if the TE cells performed like those in SP100. With improved TE materials it might be possible to reduce the number of tubes in such a design to a number like 5,000. Obviously, issues associated with developing a heat exchanger 
unit and all the components required to engineer TE materials into the unit will require a major effort in addition to development of the TE material.

\section{Recommendations}

The currently available TEG design that could be most easily applied to a fast reactor power plant would use air cooling of TE elements bonded to the liquid metal container surface. This unit would be shielded from the radiation of the reactor so the TE materials would not be impacted by the radiation. Such a design might be expected to have an efficiency of 5-10\% and would be expected to be suitable for power levels of about 10MW. The following sequence of investigation could lead to improvements in thermal efficiency that ultimately approach $25-30 \%$ in practical TEG equipment for power levels in the $25-50 \mathrm{MW}$ range.

1. Through CMS and further review of current technology identify the optimum materials for the air cooled TE elements. A single TE material would be used and bonded to the heat exchanger coolant wall and would have cooling fins, cooled by air, that would not constain the thermal expansion. Such a design might be 5-10\% efficient.

2. Identify preferred materials through integrated CMS and laboratory research and optimize segmented multiple TE materials for use in the air cooled design. This improvement might achieve a10-15\% efficiency.

3. Identify developmental materials that could be used to implement a liquid cooled TE element and its integration into a TEG design. This improvement could result in both a power level increase and an efficiencies in the $15-20 \%$ range.

4. Assuming reactor structural and fuel materials suitable for $900 \mathrm{C}$ operations are developed, identify the TE materials and TEG configuration of a liquid cooled design. This improvement would be expected to achieve $20-25 \%$ efficiency.

The order of the investigation is based on an objective of matching the cost for efficiency gain with the perceived value of having resulting efficiency. Step 1 will cost relatively little but the gain in efficiency is expected to result in a system efficiency that is still relatively low. Step 4 could be applied at Step 2 but it would be at a high cost with a gain in efficiency that would still leave the overall efficiency lower than the high development cost would justify. Step 3 is a very challenging design step and could result in a useful system, but Step 4 is probably necessary to achieve efficiencies in the range of $25-30 \%$.

High ZT Materials. The development of a new thermoelectric materials appears to be fundamental to achieving a cost competitive nuclear T/E power generator. Without a significant improvement in the figure of merit of the thermoelectric material it is not possible to conceive a cost competitive system. Based on a review of available data, it appears that research should focus initially on skutterudites. A variety of skutterudites have been explored by Jet Propulsion Laboratory (JPL). Skutterudites can be represented by the general formulae $\mathrm{LnT}_{4} \mathrm{Pn}_{12}$ or $\mathrm{TPn}_{3}$ $\left(\mathrm{Ln}=\right.$ rare earth; $\mathrm{T}=\mathrm{Fe}, \mathrm{Ru}, \mathrm{Os}, \mathrm{Co}, \mathrm{Rh}$, or Ir; \& $\mathrm{Pn}=\mathrm{P}, \mathrm{As}$, or Sb). Most recently, $\mathrm{CeFe}_{4} \mathrm{Sb}_{12}$, $\mathrm{CoSb}_{3}$, and $\mathrm{Zn}_{4} \mathrm{Sb}_{3}$ have been found to have very high dimensionless figures of merit $(\mathrm{ZT} \leq 1.4)$. For example: p-type $\beta-\mathrm{Zn}_{4} \mathrm{Sb}_{3}$ has a $\mathrm{ZT}$ of 1.4 at $675 \mathrm{~K}$; p-type $\mathrm{CeFe}_{4} \mathrm{Sb}_{3}$ has a ZT of 1.4 at 90 $0 \mathrm{~K}$; and n-type $\mathrm{CoSb}_{3}$ has ZT of 0.9 at $850 \mathrm{~K}$. This research should include both an analytical effort and experimentation. It is expected that several materials will be needed to cover the temperature range from 10 to $550^{\circ} \mathrm{C}$. 
The Jet Propulsion Laboratory in Pasadena has recently reported segmented unicouples that operate between 300 and $975 \mathrm{~K}$ and have conversion efficiencies of 15 percent [Caillat, 2000]. The p-type leg of this device uses: $\mathrm{Bi}_{0.4} \mathrm{Sb}_{1.6} \mathrm{Te}_{3}$ between 300 and $475 \mathrm{~K} ; \beta-\mathrm{Zn}_{4} \mathrm{Sb}_{3}$ between 475 and $675 \mathrm{~K}$ and $\mathrm{CeFe}_{4} \mathrm{Sb}_{12}$ between 675 and $975 \mathrm{~K}$. The n-type leg of this device uses: $\mathrm{Bi}_{2} \mathrm{Te}_{2.95} \mathrm{Se}_{0.05}$ between 300 and $475 \mathrm{~K}$ and $\mathrm{CoSb}_{3}$ between 475 and $975 \mathrm{~K}$. This device was fabricated with uniaxial hot-pressing of powdered materials, with 25 -micron thick palladium foil between the different segments of the legs. This methodology allows no interdiffusion and low contact resistance. The $\mathrm{Bi}_{2} \mathrm{Te}_{3}$-based elements were soldered to the cold shoe (copper); the skutterudites were brazed to the hot shoe (niobium) with $\mathrm{Cu}-\mathrm{Ag}$ brazing alloy. It is this type of element that would be applied in Step 2.

Given the fundamental importance of thermoelectric material and the potential of skutterudites, it is recommended that a program to address analytical modeling of the thermal, chemical and electrical properties of skutterudites be initiated. This analytical program should be coordinated with ongoing experimental efforts at the Jet Propulsion Laboratory or with equivalent laboratories in Japan. The objective would be use the analytical efforts to more quickly and efficiently identify skutterudite structures that promise an improved figure of merit. The approach would be to develop first principle models of skutterudite structures in 3-D finite element models and calibrate the figure of merit predicted by the model using known materials. Then using a theory based systematic approach to revising the model structure implement revisions that would be expected to improve the figure of merit. Identified improvements would be implemented in the laboratory and tested. The test results would be used to revise and improve the modeling efforts and selection of structural changes in the lattice. The models could be expanded as the program progresses to include the segmenting of materials. Discussion with JPL indicated that cooperative efforts between the two Laboratories would be possible. LLNL would do the CMS scope of work coordinated with JPL's laboratory work.

Combinatorial Synthesis of Skutterudites. In addition, LLNL has world recognized experience in the science and engineering of thin film materials. Troy Barbee,Jr. has developed techniques for synthesizing metastable materials by sputter deposition [Barbee, 1980]. This technique uses magnetron sputtering sources to generate the constituent multi-component $(<6)$ alloys and depositing them on various points on an intervening plane at rates proportional to the distance from each of 2 to 6 sources. This allows a continuous array of compositions to be fabricated in a relatively short amount of time. Point probes allow measurement of characteristic properties (thermal electron and acoustic conductivity, electrical conductivity, semiconductor properties). These techniques can be applied to efficiently investigate the almost unlimited permutations of materials possible in the undeveloped skutterudites. Integrating the LLNL experience and techniques with that of the JPL would accelerate the development of this promising class of thermoelectric materials.

Modeling of Long-Term Phase Stability of Candidate thermoelectric materials, insulators and conductors. Most new materials of interest for the thermoelectric devices will be metastable. Over time in the extreme temperatures of operation, one expects that precipitation of more stable phases will occur within the initial structure, resulting shifts in overall composition, physical properties, and mechanical integrity. LLNL has developed expertise in the use of computational techniques to predict the long-term behavior of complex materials as part of our nuclear waste disposal activities. These models predict diffusional changes; grain boundary formation, growth and conductivity; corrosion in the working environment; and evaporation or condensation of new phases. This expertise can be applied to the prediction of life characteristics of promising TEG 
materials, whether they are active semiconductor components, insulators, thermal or electrical conductors, or containment materials at the thermal extremes.

Electrical Insulator. In addition to the thermoelectric materials development there is a need to identify suitable electrical insulating materials that do not significantly degrade the thermal conductivity of the segmented stack. The conceptual design effort on the TEG would include a search for the material but experimental efforts would depend on the success of the analytical evaluations of the conceptual design.

Bonding materials. It appears that methods for bonding segmented assemblies of the optimum materials are available and that this approach to cascading the materials should be investigated to obtain bonding materials compatible with the thermoelectric materials. This activity would be integral to the JPL development of segmented materials.

Design optimization. The design and optimization of the heat exchanger arrangement should receive some attention early but this area should not proceed to detail design until there is evidence that high ZT material assemblies will be attainable.

The computational materials effort in the Chemistry and Materials Science (C\&MS) Department promises to enable designers with a wide variety of validated predictive tools, capable of foreseeing the long-term effects of radiation on ceramic fuel elements, cladding, semiconductors, and metallic vessel materials. This computational materials effort is also capable of performing detailed electronic structure calculations based upon band theory, thereby allowing the exact formulation of thermoelectric materials to be optimized for specific temperature ranges. The nand p-type materials used in the construction of each successive stage of the TEG cascades must be adjusted to provide the maximum Seebeck coefficient and electronic conductivity, while simultaneously minimizing thermal conductivity. Without computational optimization, the cost of such an experimental development program would be prohibitive.

An efficient set of tools based on a proper combination of quantum mechanics and statistical thermodynamics have been developed [Turchi, 1998], and are currently applied to address stability issues in a wide variety of multi-component alloys. Recently a real-space version of these tools have been implemented [Turchi, 1995, 1997, 1998; Mayou, 1998] to study systems with low symmetry (such as in the presence of interfaces or surfaces) or with no symmetry at all (such as in the case of amorphous materials). These new updates will be efficiently applicable to the prediction of materials properties, and in particular electronic transport, in thin films materials, and in two-dimensional quantum well devices. In all cases, the electronic structure information (width of the band gap, effective masses, and electronic mobility) will be combined with available experimental data to propose an improved semi-phenomenological model for predicting the conversion efficiency as a function of materials characteristics. 


\section{References}

Angrist, S. W., Direct Energy Conversion, $3^{\text {rd }}$ Ed., Allyn and Bacon, Inc., Boston, MA, 1976.

Barbee, Jr., Troy W., Keith, Douglas L., Synthesis of Metastable Materials by Sputter Deposition Techniques, Proc. TMS-AIME Alloy Phases Committee at Fall Meeting of the Metallurgical Society, Pittsburgh, Oct 5-9, 1980

Bender, K., Gogu, E., Hennig, I., Schweitzer, D., Electric Conductivity and Thermoelectric Power of Various Polypyrroles, Synthetic Metals 19, 85-88 (1987).

Birkholz, U., Grob, E., Riffel, M., Roth, H., Stohrer, U., Wittmer, W., Measurement of the Efficiency of a HMS-FeSi ${ }_{2}$ Thermoelectric Generator, Proc. XIth Intl. Conf. Thermoelectrics, K. R. Rao, Ed., Univ. Texas, Arlington, TX, Oct. 7-9, 1992.

Boikov, Yu. A., Gribanova, O. S., Danolov, V. A., Deryagina, I. M., in Proc. Intl. Conf. Thermoelectric Energy Conversion, Nancy, 1989, Sherrer, H., Sherrer, S., Eds., Inst. Natl. Polytech. de Lorraine, Nancy, 1989, pp. 18-22.

Boikov, Yu. A., Gribanov, O. S., Danilov, V. A., Kutasov, V. A., Electrophysical Parameters of Epitaxial N-Type Bi ${ }_{2} \mathrm{Te}_{3}$ Films, Sov. Phys. Solid State 33, 11 (1991) 1926-1929.

Borschevsky, A., Fluerial, J-P., Allevato, E., Caillat, T., CoSb ${ }_{3}-\mathrm{IrSb}_{3}$ Solid Solutions Preparation and Characterization, Proc. $13^{\text {th }}$ International Conference on Thermoelectrics, Kansas City, MO, B. Mathiprakasam, P. Heenan, Editors, American Institute of Physics Proceedings 316, 3-6 (1995).

Briceno, G., Chang, H., X. Sun, P. G. Schultz, X.-D. Xiang, A Class of Cobalt Oxide Magnetoresistance Materials Discovered with Combinatorial Synthesis, Science 270, 273-275 (1995).

Caillat, T., Fleurial, J-P., Borshchevsky, A., Use of Mechanical Alloying to Prepare and Investigate New Potential Thermoelectric Materials, Proc. XIth Intl. Conf. Thermoelectrics, K. R. Rao, Ed., Univ. Texas, Arlington, TX, Oct. 7-9, 1992.

Caillat, T., Fluerial, J-P., Snyder, G. J., Borschevsky, A., Progress in the Development of Segmented Thermoelectric Unicouples at the Jet Propulsion Laboratory, Materials Research Society Spring Meeting, San Francisco, CA, April, 2000.

Charles, E., Groubert, E., Boyer, A., J. Mater. Sci. Lett. 7, 575 (1988).

Cook, B. A., Harringa, J. L., Beaudry, B. J., Han, S. H., Optimization of the P/Ga Ratio in NType $\mathrm{Si}_{80} \mathrm{Ge}_{20}$ Thermoelectric Alloys Prepared by Mechanical Alloying, Proc. XIth Intl. Conf. Thermoelectrics, K. R. Rao, Ed., Univ. Texas, Arlington, TX, Oct. 7-9, 1992.

Cornish, A. J., Arrays of Inorganic Semiconducting Compounds, J. Electrochem. Soc. 106 (8) 685-689 (1959). 
Cutler, M., Fitzpatrick, R. L., Leavy, J. F., The Conduction Band of Cerium Sulfide $\mathrm{Ce}_{3-x} S_{4}$, J. Phys. Chem. Solids 24, 319-327 (1963).

Cutler, M., Leavy, J. F., Fitzpatrick, R. L., Electronic Transport in Semimetallic Cerium Sulfide, Phys. Rev. 133 (4A) A1143-A1152 (1964).

Cutler, M., Leavy, J. F., Electronic Transport in High-Resistivity Cerium Sulfide, Phys. Rev., 133 (4A) A1153-A1162 (1964).

Farmer, J. C., Barbee, T. W., Foreman, R. J., Summers, L. J., Deposition and Evaluation of Multilayer Thermoelectric Films, Proc. Symposium on Microstructures and Microfabricated Systems, $185^{\text {th }}$ Electrochem. Soc. Meeting, San Francisco, CA, May 22-27, 1994, Vol. 94-14, pp. 231-242, Electrochem. Soc., Pennington, NJ (1994).

Farmer, J. C., Barbee, T. W., Chapline, G. C., Jr., Foreman, R. J., Summers, L. J., Dresselhaus, M. S., Hicks, L. D., Sputter Deposition of Multilayer Thermoelectric Films: An Approach to the Fabrication of Two-Dimensional Quantum Wells, Thirteenth International Conference on Thermoelectrics, Kansas City, Missouri, August 30 to September 1, 1994, American Institute of Physics Proceedings 316, Eds. Mathiprakasam, B., Heenan, P., American Institute of Physics Press, New York, NY, pp. 217-225 (1994).

Farmer, J. C., Barbee, T. W., Foreman, R. J., Summers, L. J., Deposition and Evaluation of Multilayer Thermoelectric Films, Proc. Symposium on Microstructures and Microfabricated Systems, $185^{\text {th }}$ Electrochem. Soc. Meeting, San Francisco, CA, May 22-27, 1994, Electrochem. Soc., Pennington, NJ, Vol. 94-14, pp. 231-242 (1994).

Fleurial, J-P., Thermal and Electrical Transport Properties Modeling of Bi $\mathrm{Te}_{3}$-Based Alloys, Proc. XIth Intl. Conf. Thermoelectrics, K. R. Rao, Ed., Univ. Texas, Arlington, TX, Oct. 7-9, 1992.

Flueirial, J-P., Borschevsky, A., Caillat, T., Morelli, D. T., Meiusner, G. P., High Figure of Meritr in Ce-Filled Skutterudites, Proc. $15^{\text {th }}$ International Conference on Thermoelectrics, 91-95 (1996).

George, J. Pradeep, B., Solid State Commun. 56, 117 (1985).

Gladun, C., Heinrich, A., Monch, I., Schumann, J., Thomas, J., Thermoelectric Power and Sensor Application of Semiconducting CrSi and FeSi Thin Films, Proc. XIth Intl. Conf. Thermoelectrics, K. R. Rao, Ed., Univ. Texas, Arlington, TX, Oct. 7-9, 1992.

Gschneidner, K. A., Nakahara, J. F., Beaudry, B. J., Takeshita, T., Lanthanide Refractory Semiconductors Based on the $\mathrm{Th}_{3} P_{4}$ Structure, Proc. Mat. Res. Soc. 97, 359-370 (1987).

Goldsmid, H. J., Thermoelectric Refrigeration, Plenum Press, New York, NY, 1964.

Harman, T. C., PbTeSe/BiSb Short Period Superlattice as a New Thermoelectric Cooling Material, Proc. ${ }^{\text {st }}$ Natl. Thermogenic Cooler Conf., Center for Night Vision and Electro-Optics, U.S. Army, Ft. Belvoir, VA, 1992. 
Hicks, L. D., Dresselhaus, M. S., Thermoelectric Figure of Merit of a One-Dimensional Conductor, Phys. Rev. B 47 (24) 16631-16634 (1993).

Hicks, L. D., Dresselhaus, M. S., Effects of Quantum-Well Structures on the Thermoelectric Figure of Merit, Phys. Rev. B 47 (19) 12727-12731 (1993).

Hicks, L. D., Dresselhaus, M. S., BiSb/PbTeSe Superlattices as a New Thermoelectric Cooling Material: Optimization of the Figure of Merit, March 15, 1993.

Hicks, L. D., Dresselhaus, M. S., The Effects of Quantum Well Structures on the Thermoelectric Figure of Merit, Proc. $1^{\text {st }}$ Natl. Thermogenic Cooler Conf., Center for Night Vision and ElectroOptics, U.S. Army, Ft. Belvoir, VA, 1992.

Hone, J., Ellwood, I., Muno, M., Mizel, Ari, Cohen, M. L., Zettl, A., Thermoelectric Power of Single-Walled Carbon Nanotubes, Phys. Rev. Letters 80 (5) 1042-1045 (1998).

Hyun, D-B., Ha, H-P., Shim, J-D., Electrical and Thermoelectric Properties of $\mathrm{Bi}_{2} \mathrm{Te}_{3}-\mathrm{Bi}_{2} \mathrm{Se}_{3}$ Single Crystals, Proc. XIth Intl. Conf. Thermoelectrics, K. R. Rao, Ed., Univ. Texas, Arlington, TX, Oct. 7-9, 1992.

Kamarzin, A. A., Mironov, K. E., Sokilov, V. V., Malovitsky, Yu. N., Vasil'Yeva, I. G., Growth and Properties of Lanthanum and Rare-Earth Metal Sesquisulfide

Lange, R. G., Mastal, E. F., A Tutorial Review of Radioisotope Power Systems, p. 1 in A Critical Review of Space Nuclear Power and Propulsion 1984-1993, Mohamed S. El-Genk, Editor, 1 (1994).

Macklin, W. J., Moseley, P. T., On the Use of Oxides for Thermoelectric Refrigeration, Matls. Sci. Eng. B7, 111-117 (1990).

Maddison, D. S., Roberts, R. B., Unsworth, J., Thermoelectric Power of Polypyrrole, Synthetic Metals 33, 281-287 (1989).

Maddison, D. S., Unsworth, J., Electrical Conductivity and Thermoelectric Power of Polypyrrole with Different Doping Levels, Synthetic Metals 26, 99-108 (1988).

Matsubara, K., Miki, T., Nagao, K., Kishimoto, K., Nakanshi, O., Ueda, O., Fugii, K., Characterization and Thermoelectric Properties of $\mathrm{New} \beta-\mathrm{FeSi} i_{2}$ Ceramics Developed by an RFPlasma Processing in $\mathrm{O}_{2}$ and $\mathrm{SiH}_{4}$ Gases, Proc. XIth Intl. Conf. Thermoelectrics, K. R. Rao, Ed., Univ. Texas, Arlington, TX, Oct. 7-9, 1992.

Mayou, D., Turchi, P. E. A., Roche, S., Julien, J. P., Electronic Structure and Transport in Nonperiodic Systems: New $O(N)$ Methods, published in the Proceedings of the fall MRS meeting on Tight-binding Approach to Computational Materials Science, ed. by P. E. A. Turchi, A. Gonis, and L. Colombo, 491, 231 (1998).

Noro, H., Sato, K., Kagechika, H., The Thermoelectric Properties and Crystallography of Bi-SbTe-Se Thin Films Grown by Ion Beam Sputtering, J. Appl. Phys. 73, 1252-1260 (1993). 
Ohta, T., Vining, C. B., Allevato, C. E., Characteristics of a Promising New Thermoelectric Material: Ruthenium Silicide, Proc. $26^{\text {th }}$ Intersociety Energy Conversion Engineering Conf., Vol. 3, August 4-9, 1991, Boston, MA, American Nuclear Society, La Grange Park, IL, 1991, pp. 196-201.

Rosi, F. D., Thermoelectricity and Thermoelectric Power Generation, Solid-State Electronics 11, 833-868 (1968).

Roy, R. Sen, S. K., Digar, M., Bhattacharyya, S. N., Conductivity and Thermoelectric Power in Conducting Polypyrrole Films, J. Phys.: Condens. Matter 3, 7849-7856 (1991).

Stolzer, M., Stordeur, M., Properties of Magnetron Sputtered Bi $i_{0.5} S b_{1.5}$ Te $_{3}$ Films, Proc. XIth Intl. Conf. Thermoelectrics, K. R. Rao, Ed., Univ. Texas, Arlington, TX, Oct. 7-9, 1992.

Stordeur, M., Sobotta, H., Optical and Electrical Investigations of $\mathrm{N}$-Type $\mathrm{Bi}_{2} \mathrm{Se}_{3}$ Single Crystals, Proc. XIth Intl. Conf. Thermoelectrics, K. R. Rao, Ed., Univ. Texas, Arlington, TX, Oct. 7-9, 1992.

Turchi, P. E. A., Electronic Theories of Alloy Phase Stability, published in "Intermetallic Compounds: Principles and Practice, J. H. Westbrook and R. L. Fleischer eds. (John Wiley \& Sons, Ltd., New York, 1995), Vol. 1, Chap. 2, pp. 21-54 (UCRL No. JC-114106).

Turchi, P. E. A., van Ek, J., Sterne, P. A., Fe, Ru and Os Disilicides. II: Stability and Order, to be submitted to Phys. Rev. B; P. E. A. Turchi and J. van Ek, "Order-Order Transformation in FeSi2", to be submitted to Phys. Rev. B.

Turchi, P. E. A., Mayou, D., Julien, J. P., Real-space Tight-binding Approach to Stability and Order in Substitutional Multi-component Alloys, Phys. Rev. B 56, 1726 (1997).

Turchi, P. E. A., Mayou, D., Julien, J. P., Real-space Tight-binding Approach to Order in Complex Alloys, to be published in the Proceedings of the 9th International Conference on Modern Materials and Technologies (CIMTEC'98), ed. by P. Vincenzini (Techna Publishers S.R.L., Faenza), 1998.

van Ek, J., Turchi, P. E. A., Sterne, P. A., Fe, Ru and Os Disilicides. I: Electronic Structure of Ordered Compounds, Phys. Rev. B 54, 7897, 1996.

Vining, C. B., A Model for the High-Temperature Transport Properties of Heavily Doped NType Silicon-Germanium Alloys, J. Appl. Phys. 69 (1) 331-341 (1991).

Vining, C. B., Thermoelectric Limit ZT $\leq 1$ : Fact or Artifact, Proc. XIth Intl. Conf. Thermoelectrics, K. R. Rao, Ed., Univ. Texas, Arlington, TX, Oct. 7-9, 1992.

Voss, S. S., SNAP Reactor Overview, AFWL TN-84-14 (1984).

Wagner, A. V, Foreman, R. J., Summers, L. J., Barbee, T. W., Farmer, J. C., Multilayer Thermoelectric Films: A Strategy for the Enhancement of ZT, Proc. 30 ${ }^{\text {th }}$ Intersociety Energy Conversion Engineering Conference, Orlando, Florida, July 31 through August 4, 1995, Vol. 3, pp. 87-92 (1995). 
Wagner, A. V, Foreman, R. J., Summers, L. J., Barbee, T. W., Farmer, J. C., Multilayer Thin Film Thermoelectrics Produced by Sputtering, Proc. XIV International Conference on Thermoelectrics, St. Petersburg, Russia, June 27-30, 1995, Vedernikov, M. V., Fedorov, M. I., Kaliazin, A. E., Ed., A. F. Ioffe Physical-Technical Institute, St. Petersburg, Russia, pp. 283-287 (1995).

Wagner, A. V, Foreman, R. J., Summers, L. J., Barbee, T. W., Farmer, J. C., Synthesis and Evaluation of Thermoelectric Multilayer Film, Proc. XV International Conference on Thermoelectrics, Pasadena, California, March 26-29 (1996).

Wagner, A.V, Foreman, R.J., Summers, L.J., Barbee, T.W., Farmer, J.C., Fabrication and Testing of Thermoelectric Thin Film Devices, Proc. XV International Conference on Thermoelectrics, Pasadena, California, March 26-29 (1996).

Wakaki, M., Ohkubo, O., Okumura, T., Yamashita, M., Kibayashi, Y., Yamaguchi, T., FarInfrared Characterization of Narrow Gap Semiconductors for Thermoelectric Cooling, Proc. XIth Intl. Conf. Thermoelectrics, K. R. Rao, Ed., Univ. Texas, Arlington, TX, Oct. 7-9, 1992.

Wood, C., Materials for Thermoelectric Energy Conversion, Rep. Prog. Phys. 51, 459-539 (1988).

X.-D. Xiang, X. Sun, G. Briceno, Y. Lou, K-A. Wang, H. Chang, W. G. Wallace-Freedman, S.W. Chen, P. G. Schultz, A Combinatorial Approach to Materials Discovery, Science 268, 17381740 (1995).

Yoon, C. O., Na, B. C., Park, Y. W., Thermoelectric Power and Conductivity of the StretchOriented Polyacetylene Film Doped With $\mathrm{MoCl}_{5}$, Synthetic Metals 41-43, 125-128 (1991). 